\title{
Association between the 2-bp deletion polymorphism in the duplicated version of the alpha7 nicotinic receptor gene and P50 sensory gating
}

\author{
Rachel H Flomen 1,6,8, Madiha Shaikh ${ }^{2,6}$, Muriel Walshe ${ }^{2}$, Katja Schulze ${ }^{2}$, Mei-Hua Hall ${ }^{3}$, Marco Picchioni ${ }^{2,4}$, \\ Fruhling Rijsdijk ${ }^{5}$, Timothea Toulopoulou ${ }^{2}$, Eugenia Kravariti ${ }^{2}$, Robin M Murray ${ }^{2}$, Philip Asherson ${ }^{5}$, \\ Andrew J Makoff ${ }^{\star, 1,7}$ and Elvira Bramon ${ }^{2,7}$
}

There is considerable evidence implicating the $15 q 13.3$ region in neuropsychiatric disorders, with the $\alpha 7$ nicotinic receptor gene CHRNA7 the most plausible candidate. This region has multiple duplications and many copy number variants (CNVs). A common CNV involves a partial duplication of CHRNA7 (CHRFAM7A), which occurs in either orientation. We examined the distribution of these alternative genomic arrangements in a large cohort of psychiatric patients, their relatives and controls using the 2-bp deletion polymorphism as a marker for the orientation of CHRFAM7A. We investigated three common alleles for association with psychosis and with the P50 sensory gating deficit, which is strongly associated with psychosis and strongly linked to $15 q 13.3$. We found significant within-family association with P50 (empirical $P=0.004$ ), which is robust to population stratification. Most of the effect came from the 2-bp deletion allele, which tags the variant of CHRFAM7A in the same orientation as CHRNA7. This allele is associated with the presence of the P50 sensory gating deficit (empirical

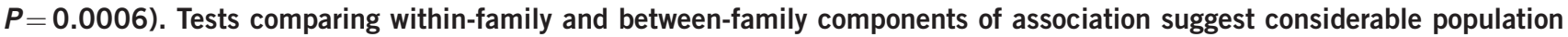
stratification in the sample. We found no evidence for association with psychosis, but this may reflect lower power using this phenotype. Four out of six previous association studies found association of different psychiatric phenotypes with the same 2-bp deletion allele.

European Journal of Human Genetics (2013) 21, 76-81; doi:10.1038/ejhg.2012.81; published online 16 May 2012

Keywords: CHRFAM7A; schizophrenia; bipolar disorder

\section{INTRODUCTION}

The $15 \mathrm{q} 13.3$ region has been implicated in several neurological and psychiatric disorders. The P50 sensory gating deficit, one of the best supported endophenotypes of schizophrenia and bipolar disorder, is strongly linked to this region, ${ }^{1}$ as are two idiopathic epilepsies. ${ }^{2,3}$ Of the many attempts to demonstrate linkage of schizophrenia and bipolar disorder to this region, two studies showed linkage to bipolar disorder, ${ }^{4,5}$ but several found either weak $^{6-10}$ or no linkage to schizophrenia. ${ }^{1-13}$ Both schizophrenia and bipolar disorder have also shown association with $15 \mathrm{q} 13.3$ markers. ${ }^{14}$ The most plausible candidate gene in $15 \mathrm{q} 13.3$ for the major psychoses and epilepsies is CHRNA7, the $\alpha 7$ nicotinic acetylcholine receptor gene. ${ }^{15,16}$ However, $15 q 13.3$ is a complex region in the midst of many large segmental duplications. ${ }^{17,18}$ These are highly variable, resulting in several different copy number variants (CNVs).

One common CNV includes part of CHRNA7 (exons 5-10), which is duplicated in the hybrid gene CHRFAM7A that occurs in most individuals. We found weak evidence for association of the absence of one copy of CHRFAM7A with psychosis in a large Scottish sample. ${ }^{19}$
When present, CHRFAM7A can occur in either orientation, with one orientation strongly associated with the common 2-bp deletion polymorphism in exon $6,{ }^{20}$ found only in CHRFAM7A (Supplementary Figure 1a). We found no association of the 2-bp deletion with schizophrenia in the above study, but an association with schizophrenia has since been reported. ${ }^{21}$ Other studies have found that the 2-bp deletion is associated with bipolar disorder, ${ }^{22} \mathrm{P} 50$ sensory gating deficit ${ }^{23}$ and deficits in episodic memory, ${ }^{24}$ another endophenotype proposed for schizophrenia. Recent genome-wide scans for CNVs showed that much rarer CNVs at 15q13.3, usually involving deletion of $\sim 2 \mathrm{Mb}$ from CHRFAM7A to CHRNA7, are overrepresented in many neurological and psychiatric disorders. These deletions are very rare in the general population $(\sim 0.02 \%)$, but more common in schizophrenia, autism/developmental disorders and some forms of intellectual impairment $(\sim 0.2-0.3 \%)$ and even more common in idiopathic generalized epilepsy $(\sim 1.0 \%))^{25-28}$ These $\sim 2-\mathrm{Mb}$ microdeletions lead to the loss of CHRNA7 and five other genes (Supplementary Figure 1a), but smaller variants that show a similar range of phenotypes remove only CHRNA7 and one other

${ }^{1}$ Department of Clinical Neuroscience, Institute of Psychiatry, King's College London, London, UK; ${ }^{2}$ NIHR Biomedical Research Centre for Mental Health at the South London and Maudsley NHS Foundation Trust and Institute of Psychiatry, King's College London, London, UK; ${ }^{3}$ Psychology Research Laboratory, Harvard Medical School, McLean Hospital, Belmont, MA, USA; ${ }^{4}$ St Andrews Academic Centre, Institute of Psychiatry, Northampton, UK; ${ }^{5}$ Social, Genetic Developmental Psychiatry Research Centre, Institute of Psychiatry, King's College London, London, UK

*Correspondence: Dr A Makoff, Department of Clinical Neuroscience, Institute of Psychiatry, King's College London, 1, Windsor Walk, Denmark Hill, London, SE5 8AF, UK.

Tel: + 44207848 0638; Fax: + 44207848 0051; E-mail: andrew.makoff@kcl.ac.uk

6These authors contributed equally to this work.

${ }^{7}$ These authors jointly directed this work.

8Present address: Department of Medical \& Molecular Genetics, King's College London School of Medicine, Tower Wing, Guy's Hospital, London, UK

Received 14 September 2011; revised 16 March 2012; accepted 27 March 2012; published online 16 May 2012 
gene. ${ }^{29}$ These observations strongly implicate the CHRNA7 region in schizophrenia and other neuropsychiatric disorders.

P50 sensory gating is an EEG signal that is believed to reflect the ability to filter out repetitive stimuli and prevent information overload. ${ }^{30-32}$ The P50 wave is generated in a conditioning-testing paradigm where the first stimulus activates or conditions the inhibition phenomenon, whereas the second tests its strength. Normally, individuals reduce the second (test) response relative to the first (condition) waves. The diminished test P50 wave is thought to be due to activation of inhibitory neural circuitry by the conditional P50 stimuli. ${ }^{133-35}$ Compared with controls, patients with schizophrenia and psychotic bipolar disorder have a relatively larger P50 response to the second stimulus, from only $20-50 \%$ suppression. ${ }^{31,36-47}$ Clinically unaffected first-degree relatives of patients with schizophrenia and psychotic bipolar disorder also have poor P50 suppression, suggesting that this might act as a marker of genetic risk for these disorders, ${ }^{46-53}$ as it is heritable. ${ }^{54-57}$

We have examined the effects of CHRFAM7A CNV/2 bp deletion variants on the major psychoses and the P50 sensory gating deficit. We utilized a large group of families, twin pairs and controls including several family members diagnosed with schizophrenia or psychotic bipolar disorder, where P50 measurements were made.

\section{METHODS}

The sample

The sample included 871 Caucasian individuals from the national Maudsley Family and Twin Psychosis Studies. A subgroup of these $(N=445)$ underwent EEG recordings from which were derived the P50 suppression ratios, computed as the ratio of testing to conditioning wave amplitudes (T/C) expressed as a percentage. Patients satisfied DSM-IV criteria for schizophrenia, schizoaffective disorder or psychotic bipolar disorder. Their unaffected firstdegree relatives were free of any psychotic illness whereas the controls had no personal or family history of psychosis. Subjects were excluded if they had a neurological disorder, head injury with loss of consciousness exceeding $10 \mathrm{~min}$ or diagnosis of alcohol or substance dependence in the previous 12 months. The studies were approved by the Joint South London and Maudsley and the Institute of Psychiatry NHS Research Ethical Committee or the South East Research Ethics Committee. All participants gave written informed consent.

\section{Clinical assessments and P50 measurements}

Clinical assessment, P50 measurements and analysis were performed as described in detail elsewhere. ${ }^{31}$

\section{Genotyping}

Genotyping for the CHRFAM7A CNV/2 bp deletion polymorphisms required two sequential assays. ${ }^{19}$ Presence of the 2-bp deletion was determined by limited cycle PCR using ABI3130 and Genemapper v3.0 software (Life Technologies Limited, Paisley, UK). Each sample was assayed at least twice to identify three genotypes (13,23 and 33) where the 2-bp deletion is present, with alleles defined as $1=$ null CHRFAM7A, $2=$ wild-type CHRFAM7A and $3=$ CHRFAM7A with 2 bp deletion (Supplementary Figures 1a, b). Samples without a 2-bp deletion were assayed by a Taqman assay (Life Technologies Limited) to determine the copy number of CHRFAM7A (at least three determinations per sample) to identify the remaining three genotypes (11, 12 and 22).

Genotyping was performed and analyzed 'blind' to patient identity. Several patients had more than one DNA sample. These and monozygous (MZ) pairs accounted for 606 genotyped samples, which were compared to assess genotyping reproducibility, giving an error rate of $6 \%$. Duplicate or MZ pairs discordant for genotype were excluded.

\section{Statistical analyses}

Significance of association of the CNV/2 bp deletion polymorphisms with clinical groups was performed by $\chi^{2}$-tests, including only one twin from each
MZ pair concordant for psychosis but excluding discordant MZ pairs. In initial analyses, these tests were also applied to P50, as two categorical groups: P50 T/C ratios $>60$ versus $<40 \%$, and including one MZ twin per pair using each average T/C ratio. Family-based association analyses were performed on categorical phenotypes by the transmission disequilibrium test (TDT) using Transmit (https://www-gene.cimr.cam.ac.uk/staff/clayton/software/). ${ }^{58}$ Transmit uses parental genotypes, when present, but can use siblings to derive possible parental genotypes when absent. As Transmit will not accept twinships, dizygous (DZ) twins were entered as siblings while one twin per MZ pair were entered as above. To perform tests for association on continuous phenotype scores we used QTDT (http://www.sph.umich.edu/csg/abecasis/QTDT/), ${ }^{59,60}$ which incorporates a modified form of TDT. QTDT will construct possible parental genotypes where absent and accepts all types of sibships. It can utilize components variance modeling, which we used as recommended for samples including families with multiple offspring. ${ }^{60}$ QTDT assesses both between-family and within-family components of association to provide three tests of association: 'total' combines both components but is invalid in the presence of population stratification, 'within' gives the within-family component and is robust to stratification and 'stratification' compares the components to test for stratification.

\section{RESULTS}

The sample

The sample comprises patients diagnosed with a major psychosis (mainly schizophrenia or bipolar disorder), their families (including co-twins), controls and control twin pairs, all of whom were white Caucasians. Table 1 shows the demographic matching between patients, relatives and controls. As is often seen with studies of psychosis, the patient group had significantly more males than the control group. The P50 subset illustrates the well-established strength of association between P50 and psychosis, ${ }^{46,61,62}$ with very strong associations between patients and controls $\left(P=5 \times 10^{-9}\right)$, and between relatives and controls $\left(P=6 \times 10^{-6}\right)$.

\section{Association study by patient group}

Comparison of the distribution of the three alleles among the three patient groups showed no significant association (Table 2). The distributions of the six genotype frequencies (see Supplementary Table 1) were all in Hardy-Weinberg equilibrium (HWE), and there was also no significant association. As case-control association studies are vulnerable to population stratification, we investigated possible family-based association. This was performed by TDT, which compares the transmission of alleles from heterozygous parents to affected offspring. As shown in Table 3 (top), there was no evidence for family-based association with psychosis.

\section{Association study by P50}

Allele frequencies for individuals with P50 data are shown in Table 4. In a preliminary analysis, we compared the allele distributions between individuals with a $\mathrm{T} / \mathrm{C}$ ratio $>60 \%$ (generally regarded as abnormal) with those $<40 \%$ (within the normal range). As shown in Table 4, there was no significant difference between allele frequencies. The distributions of genotype frequencies are shown in Supplementary Table 2, with all genotypes in HWE.

As with comparisons between patient groups, this type of association analysis can be compromised by population stratification. Furthermore, it does not utilize all available power of the sample as (a) it reduces the full range of $\mathrm{T} / \mathrm{C}$ ratios to two discrete groups and (b) it does not utilize the family relationships. To overcome these limitations, we analysed the data by QTDT, which compares transmission of each allele from heterozygous parents with offspring scored with the full range of $\mathrm{T} / \mathrm{C}$ ratios. 
Table 1 Details of sample, all of whom were white Caucasians

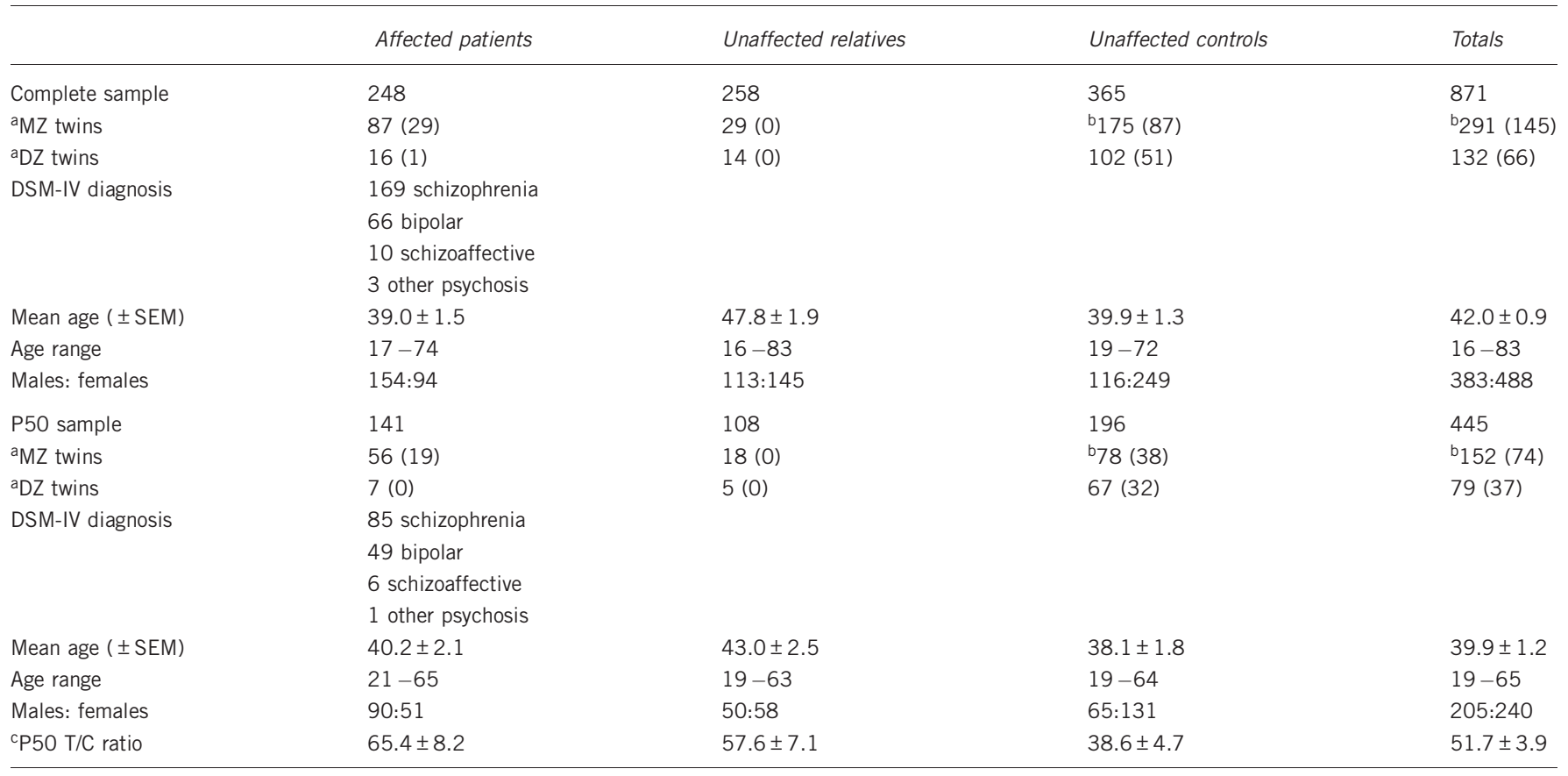

Abbreviations: DZ, dizygous; MZ, monozygous; T/C, ratio of testing to conditioning wave amplitudes.

aNumber of twins for each group with number of twin pairs shown in brackets.

bIncludes one triplet.

'Significance by $t$-tests: patients versus controls: $P=5 \times 10^{-9}$; patients versus relatives: $P=0.2$; relatives versus controls: $P=6 \times 10^{-6}$.

Table 2 Comparison of allele frequencies by patient group

\begin{tabular}{lccc}
\hline Allele & Affected patients & Unaffected relatives & Unaffected controls \\
\hline 1 & $44(0.13)$ & $55(0.14)$ & $54(0.11)$ \\
2 & $141(0.42)$ & $157(0.41)$ & $226(0.47)$ \\
3 & $151(0.45)$ & $170(0.45)$ & $206(0.42)$ \\
Totals & 336 & 382 & 486 \\
\hline
\end{tabular}

Alleles defined as 1 (null CHRFAM7A), 2 (wt CHRFAM7A), 3 (CHRFAM7A with 2 bp deletion). Global significance for overall allele frequency comparisons: patients versus controls: $\gamma^{2}=1.87$, 2 degree of freedom (df), $P=0.4$; relatives versus controls: $\chi^{2}=3.48,2 \mathrm{df}, P=0.18$.

QTDT has three tests of association: 'total', 'within' and 'stratification' (see Methods). The tests of total association were not significant (Table 5). By contrast, the tests of within-family association, which are robust to population stratification, were clearly significant. The empirical measurement of significance for global association ( $P=0.004$, based on 10000 permutations) is much stronger than the calculated value $(P=0.02)$, and is regarded as more reliable ${ }^{60}$ as it makes no assumptions regarding normality of distribution or degrees of freedom (Table 5). When each allele was considered alone, allele 3 (empirical $P=0.0006$ ) and, to a much lesser extent, allele 1 (empirical $P=0.03$ ) were both significant. The tests for stratification were also significant for global association (empirical $P=0.04$ ) and allele 3 alone (empirical $P=0.004$ ). We also modeled the effects of psychosis diagnosis, sex or age as covariates, which made very little difference to the tests of association (Supplementary Table 3).

To provide model-free evidence for the within-family association found for P50 and to identify its direction, we dichotomized the P50 scores as for the initial analysis and performed TDT using Transmit. Unsurprisingly, the loss of twin data (used in QTDT) and the loss of the full range of P50 scores caused considerable loss of power.
Table 3 Comparison of transmissions to offspring affected with psychosis or $\mathrm{T} / \mathrm{C}$ ratio $>60 \%$

\begin{tabular}{lcccc}
\hline Allele & Phenotype & $\begin{array}{c}\text { Observed } \\
\text { transmissions }\end{array}$ & $\begin{array}{c}\text { Expected } \\
\text { transmissions }\end{array}$ & $\begin{array}{c}\text { a Significance } \\
\left(\chi^{2}, d f, P\right)\end{array}$ \\
\hline 1 & Psychosis & $42(0.13)$ & $42(0.13)$ & $\chi^{2}=0.01,1 \mathrm{df}, P=0.9$ \\
2 & $136(0.43)$ & $136(0.43)$ & $\chi^{2}=0.00,1 \mathrm{df}, P=1.0$ \\
3 & $142(0.44)$ & $142(0.44)$ & $\chi^{2}=0.00,1 \mathrm{df}, P=1.0$ \\
Totals & 320 & 320 & \\
1 & P50 T/C $>60 \%$ & $22(0.11)$ & $26(0.13)$ & $\chi^{2}=2.31,1 \mathrm{df}, P=0.13$ \\
2 & & $82(0.40)$ & $85(0.42)$ & $\chi^{2}=0.74,1 \mathrm{df}, P=0.4$ \\
3 & $100(0.49)$ & $93(0.46)$ & $\chi^{2}=3.76,1 \mathrm{df}, P=0.05$ \\
Totals & 204 & 204 & \\
\hline
\end{tabular}

Abbreviations: df, degree of freedom; T/C, ratio of testing to conditioning wave amplitudes. For psychosis, global significance: $\gamma^{2}=0.01,2 \mathrm{df}, P=1.0$

For P50, global significance: $\chi^{2}=4.41,2 \mathrm{df}, P=0.11$.

asignificance determined by transmission disequilibrium test.

Nominally significant $P$-value shown in bold.

Table 4 Comparison of allele frequencies by P50 T/C ratios

\begin{tabular}{|c|c|c|c|c|}
\hline Allele & $\begin{array}{l}\text { All } T / C \\
\text { ratios }\end{array}$ & $\begin{array}{c}\text { T/C ratios } \\
>60 \%\end{array}$ & $\begin{array}{l}\text { T/C ratios } \\
<40 \%\end{array}$ & a Significance \\
\hline 1 & $84(0.12)$ & $28(0.12)$ & $38(0.13)$ & $\chi^{2}=0.27,1 \mathrm{df}, P=0.6$ \\
\hline 2 & $298(0.44)$ & $95(0.40)$ & $132(0.46)$ & $\begin{array}{l}\chi^{2}=2.06,1 \mathrm{df} \\
P=0.15\end{array}$ \\
\hline 3 & $296(0.44)$ & $115(0.48)$ & $116(0.41)$ & $\begin{array}{l}\chi^{2}=3.17,1 \mathrm{df} \\
P=0.07\end{array}$ \\
\hline Totals & 678 & 238 & 286 & \\
\hline
\end{tabular}

Abbreviations: $\mathrm{df}$, degree of freedom; $\mathrm{T} / \mathrm{C}$, ratio of testing to conditioning wave amplitudes. aGlobal significance for allele frequency comparisons $\mathrm{T} / \mathrm{C}$ ratios $>60 \%$ versus $<40 \%$ : $\chi^{2}=3.18,2 \mathrm{df}, P=0.2$. 
Table 5 Quantitative transmission disequibrium test results for P50 T/C ratio

\begin{tabular}{|c|c|c|c|}
\hline Allele & $\begin{array}{l}\text { Association } \\
\text { test }\end{array}$ & ${ }^{a}$ Calculated significance & ${ }^{\mathrm{b}}$ Empirical significance \\
\hline $\begin{array}{l}\text { All } \\
1 \\
2 \\
3\end{array}$ & total & $\begin{array}{l}\chi^{2}=4.29,2 \mathrm{df}, P=0.12 \\
\chi^{2}=2.44,1 \mathrm{df}, P=0.12 \\
\chi^{2}=0.74,1 \mathrm{df}, P=0.4 \\
\chi^{2}=3.44,1 \mathrm{df}, P=0.06\end{array}$ & \\
\hline $\begin{array}{l}\text { All } \\
1 \\
2 \\
3\end{array}$ & within & $\begin{array}{l}\chi^{2}=7.62,2 \mathrm{df}, \boldsymbol{P}=\mathbf{0 . 0 2} \\
\chi^{2}=4.35,1 \mathrm{df}, \boldsymbol{P}=\mathbf{0 . 0 4} \\
\chi^{2}=0.62,1 \mathrm{df}, P=0.4 \\
\chi^{2}=7.07,1 \mathrm{df}, \boldsymbol{P}=\mathbf{0 . 0 0 8}\end{array}$ & $\begin{array}{l}\boldsymbol{P}=\mathbf{0 . 0 0 4}(10,000 \text { permutations }) \\
\boldsymbol{P}=\mathbf{0 . 0 3}(10,000 \text { permutations }) \\
\boldsymbol{P}=\mathbf{0 . 0 0 0 6}(100,000 \text { permutations })\end{array}$ \\
\hline $\begin{array}{l}\text { All } \\
1 \\
2 \\
3\end{array}$ & stratification & $\begin{array}{l}\chi^{2}=4.06,2 \mathrm{df}, P=0.13 \\
\chi^{2}=2.09,1 \mathrm{df}, P=0.15 \\
\chi^{2}=0.24,1 \mathrm{df}, P=0.6 \\
\chi^{2}=4.34,1 \mathrm{df}, P=\mathbf{0 . 0 4}\end{array}$ & $\begin{array}{l}\boldsymbol{P}=0.04(1,000 \text { permutations }) \\
P=0.13(1,000 \text { permutations }) \\
\boldsymbol{P}=\mathbf{0 . 0 0 4}(10,000 \text { permutations })\end{array}$ \\
\hline
\end{tabular}

Abbreviation: T/C, ratio of testing to conditioning wave amplitudes.

aCalculated significance was derived from the differences in log likelihood scores $\left(\gamma^{2}\right)$ and

a Calculated significance was derived from the differences in log
degrees of freedom (df) between the null and alternative models.

${ }^{b}$ Empirical significance was derived from multiple permutation tests, number of tests as shown. Nominally significant $P$-values shown in bold.

Nonetheless, nominally significant association with allele 3 was detected $\left(\chi^{2}=3.76,1\right.$ degree of freedom (df), $P=0.05$; Table 3, bottom). These results support the QTDT within-family tests of association and show that the direction is of elevated P50 scores associated with increased transmission of allele 3 .

\section{DISCUSSION}

Within-family tests provide evidence for association of the CHRFAM7A variants with $\mathrm{P} 50 \mathrm{~T} / \mathrm{C}$ ratio, with most of the association between elevated ratios and raised allele 3 ( 2 bp deletion) frequencies. However, $\chi^{2}$-tests and tests combining between- and within-family associations, that do not control for stratification, were not significant, although such tests considering allele 3 alone almost reached nominal significance. This pattern of findings could indicate a type I error in the within-family tests of association. However, they may also be explained by population stratification for the genetic variants investigated here, which would invalidate between-family tests, whereas within-family tests remain robust. Supporting this, we found that tests of population stratification for these genetic variants were significant, indicating that only the within-family association test is valid and suggesting that significant between-family association may have been masked by population stratification. ${ }^{59}$ Similar results were found for other associations. ${ }^{63,64}$

Although our cohort were all white Caucasians, some genetic heterogeneity within this ethnic group would not be surprising. Investigating the sample with a panel of ethnically specific SNPs might clarify this issue, although CHRFAM7A variants investigated here show a wide allele frequency variation between ethnicities, ${ }^{21}$ suggesting that stratification effects may be particularly pronounced for these variants. Although population stratification is a plausible explanation for the difference between within- and between-family tests of association, other factors may be involved.

One potential source of error could be incorrect genotype calls, which are known to increase type I errors in family-based association studies. ${ }^{65,66}$ Therefore, the observed within-family association might be because of genotype errors that we estimated at $6 \%$. Using simulated error rates up to $10 \%$ in SNPs, type I errors were found to be highest where both alleles had very different frequencies and minimal with alleles of equal frequency, ${ }^{65}$ with similar observations for multiallelic polymorphisms. ${ }^{66}$ Our strongest association was due to an excess of allele 3 transmissions from 13 and 23 heterozygotes.
Allele 3 frequency is close to the combined frequencies of the other two alleles, where the error-induced type I error rate is expected to be low. This suggests that genotype errors are unlikely to account for the significant within-family association.

Unlike P50, the psychosis phenotype showed no evidence for association with the CHRFAM7A alleles investigated. This is consistent with the hypothesis that endophenotypes may confer greater power to detect association than the disease phenotype, where the variance is spread over a wider range of genetic and environmental factors. Furthermore, the psychosis phenotype is not amenable to quantitative family-based studies such as QTDT, which under certain circumstances may also have more power than categorical association tests.

Of the six previous studies involving CHRFAM7A variants and either a psychosis phenotype or endophenotype, ${ }^{19,21-24,67}$ four found a significant association with the 2-bp deletion. However, there is no consistency with the phenotype involved. Raux et $a^{23}$ found a higher frequency of the 2-bp deletion allele in individuals with a high P50 T/C ratio, but no association with schizophrenia. Our data support these results. By contrast, Sinkus et $a l^{21}$ found no association with P50, but significant association with schizophrenia in both Caucasians and African-Americans. Dempster et $a l^{24}$ found an association between the same allele and episodic memory deficits, a possible endophenotype of schizophrenia. Finally, Hong et $a^{22}$ found an association between the 2-bp deletion and bipolar disorder. It is possible that at least some of these four studies may be detecting the same genetic effect as in the present study.

The biological effect of the 2-bp deletion in CHRFAM7A is difficult to infer as the role of CHRFAM7A, found uniquely in humans, is poorly understood. The gene is transcribed, as mRNA sequences have been detected. ${ }^{17,68}$ Two recent studies demonstrated that co-expression of CHRFAM7A with CHRNA7 significantly reduced acetylcholine currents. ${ }^{69,70}$ This appeared to be a posttranslational effect, and the presence of the 2-bp deletion in exon 6 of CHRFAM7A further reduced these currents. ${ }^{70}$ The CHRFAM7A sequence predicts two different potential proteins that contain some $\alpha 7$ nicotinic receptor amino-acid sequence, one being prevented by the 2-bp deletion, whereas the other is only possible in its presence. However, there is no evidence for either protein.

Another possibility is that the 2-bp deletion is linked to a functional polymorphism. Previously, we found that CHRFAM7A commonly exists in either orientation (Supplementary Figure 1a) and that the 2-bp deletion is strongly associated with CHRFAM7A in the same orientation as CHRNA7. ${ }^{20}$ This suggests that the 2-bp deletion tags the orientation of CHRFAM7A, although this does depend on a single study. It is possible that the orientation of the gene might affect its expression, as the DNA environment upstream of the likely location of the CHRFAM7A promoter would be altered by the inversion. However, there is an alternative way in which the orientation of CHRFAM7A might exert a biological effect. The rare $15 \mathrm{q} 13.3$ microdeletion is strongly associated with many neuropsychiatric conditions, including schizophrenia. ${ }^{25-27}$ This deletion is recurrent and probably arises from non-allelic homologous recombination when two direct repeats misalign during meiosis. Two large direct repeats likely to be responsible include CHRNA7 and CHRFAM7A $^{71}$ (see Supplementary Figure 1a). The occurrence of these two genes in the same orientation therefore predisposes, in a very small minority of cases, to the $15 \mathrm{q} 13.3$ microdeletion in the next generation. A similar misalignment of these direct repeats might occur during DNA replication. An accumulation of such 15q13.3 microdeletions in key neural cells might mimic some of the 
phenotypes associated with patients who have inherited this deletion. If it occurs, it would be limited to individuals with at least one copy of CHRFAM7A in the CHRNA7 orientation. Our finding of an association between the P50 sensory gating deficit with the 2-bp deletion allele provides an indirect evidence for an association with this orientation of CHRFAM7A, which is consistent with this intriguing possible mechanism.

\section{CONFLICT OF INTEREST}

The authors declare no conflict of interest

\section{ACKNOWLEDGEMENTS}

We thank all study participants. This work was supported by NARSAD awards to AM and EB and Wellcome Trust Research Training Fellowships to MP and EB, with further support provided by the Wellcome Trust and NIHR. EB holds a MRC new investigator award. We also thank R Pinto for her advice and assistance with QTDT.

1 Freedman $\mathrm{R}$, Coon $\mathrm{H}$, Myles-Worsley $\mathrm{M}$ et al: Linkage of a neurophysiological defici in schizophrenia to a chromosome 15 locus. Proc Natl Acad Sci USA 1997; 94 587-592.

2 Elmslie FV, Rees M, Williamson MP et al: Genetic mapping of a major susceptibility locus for juvenile myoclonic epilepsy on chromosome 15q. Hum Mol Genet 1997; 6: 1329-1334.

3 Neubauer BA, Fiedler B, Himmelein B et al: Centrotemporal spikes in families with rolandic epilepsy: linkage to chromosome 15q14. Neurology 1998; 51: 1608-1612.

4 Edenberg HJ, Foroud T, Conneally PM et al: Initial genomic scan of the NIMH genetics initiative bipolar pedigrees: Chromosomes 3, 5, 15, 16, 17, and 22. Am J Med Genet 1997; 74: 238-246.

5 Turecki G, Grof P, Grof E et al: Mapping susceptibility genes for bipolar disorder: a pharmacogenetic approach based on excellent response to lithium. Mol Psychiatry 2001; 6: 570-578.

6 Kaufmann CA, Suarez B, Malaspina D et al: NIMH Genetics Initiative Millenium Schizophrenia Consortium: linkage analysis of African-American pedigrees. Am J Med Genet 1998; 81: 282-289.

7 Leonard S, Gault J, Moore T et al: Further investigation of a chromosome 15 locus in schizophrenia: analysis of affected sibpairs from the NIMH Genetics Initiative. Am J Med Genet 1998; 81: 308-312.

8 Riley BP, Makoff A, Mogudi-Carter M et al: Haplotype transmission disequilibrium and evidence for linkage of the CHRNA7 gene region to schizophrenia in Southern African Bantu families. Am J Med Genet 2000; 96: 196-201.

9 Gejman PV, Sanders AR, Badner JA, Cao Q, Zhang J.: Linkage analysis of schizophrenia to chromosome 15. Am J Med Genet 2001; 105: 789-793.

10 De Luca V, Wong AHC, Muller D, Wong GWH, Tyndale R, Kennedy JL: Evidence of association between smoking and alpha7 nicotinic receptor subunit gene in schizophrenia patients. Neuropsychopharmacology 2004; 29: 1522-1526.

11 Neves-Pereira M, Bassett AS, Honer WG, Lang D, King NA, Kennedy JL: No evidence for linkage of the CHRNA7 gene region in Canadian schizophrenia families. Am J Med Genet 1998; 81: 361-363.

12 Curtis L, Blouin JL, Radhakrishna $U$ et al: No evidence for linkage between schizophrenia and markers at chromosome 15q13-14. Am J Med Genet 1999; 88: 109-112.

13 Meyer J, Ortega G, Schraut $\mathrm{K}$ et al: Exclusion of the neuronal nicotinic acetylcholine receptor alpha7 subunit gene as a candidate for catatonic schizophrenia in a large family supporting the chromosome 15q13-22 locus. Mol Psychiatry 2002; 7: 220-223.

14 Stassen HH, Bridler R, Hagele S et al: Schizophrenia and smoking: evidence for a common neurobiological basis? Am J Med Genet 2000; 96: 173-177.

15 Leonard S, Freedman R: Genetics of chromosome 15q13-q14 in schizophrenia. Biol Psychiatry 2006; 60: 115-122.

16 Mulley JC, Dibbens LM: Chipping away at the common epilepsies with complex genetics: the 15q13.3 microdeletion shows the way. Genome Med 2009; 1: 33 .

17 Riley BP, Williamson M, Collier DA, Wilkie H, Makoff AJ A: 3Mb map of a large segmental duplication overlapping a7 nicotinic acetylcholine receptor gene (CHRNA7) at human 15q13- q14. Genomics 2002; 79: 197-209.

18 Makoff A, Flomen RH: Detailed analysis of 15q11-q14 sequence fully reveals large segmental duplications at breakpoints for Prader -Willi and Angelman syndromes and other 15q genomic disorders. Genome Biol 2007; 8: R114.1-R114.16.

19 Flomen RH, Collier DA, Osborne S et al: Association study of CHRFAM7A copy number and 2 bp deletion polymorphisms with schizophrenia and bipolar affective disorder. Am J Med Genet 2006; 141: 571-575.
20 Flomen RH, Davies AF, Di Forti M et al: The copy number variant involving part of the alpha 7 nicotinic receptor gene (CHRNA7) contains a polymorphic inversion. Eur J Hum Genet 2008; 16: 1364-1371.

21 Sinkus ML, Lee MJ, Gault J et al: A 2-base pair deletion polymorphism in the partial duplication of the alpha7 nicotinic acetylcholine gene (CHRFAM7A) on chromosome $15 q 14$ is associated with schizophrenia. Brain Res 2009; 1291: 1-11.

22 Hong CJ, Lai IC, Liou LL, Tsai SJ: Association study of the human partially duplicated alpha7 nicotinic acetylcholine receptor genetic variant with bipolar disorder. Neurosci Lett 2004; 355: 69-72.

23 Raux G, Bonnet-Brilhault F, Louchart S et al: The -2 bp deletion in exon 6 of the 'alpha 7-like' nicotinic receptor subunit gene is a risk factor for the P50 sensory gating deficit. Mol Psychiatry 2002; 7: 1006-1011.

24 Dempster EL, Toulopoulou T, McDonald C et al: Episodic memory performance predicted by the 2 bp deletion in exon 6 of the 'alpha 7-like' nicotinic receptor subunit gene. Am J Psychiatry 2006; 163: 1832-1834.

25 Stefansson H, Rujescu D, Cichon S et al: Large recurrent microdeletions associated with schizophrenia. Nature 2008; 455: 232-236.

26 International Schizophrenia Consortium. Rare chromosomal deletions and duplications increase risk of schizophrenia. Nature 2008; 455: 237-241.

27 Helbig I, Mefford HC, Sharp AJ et al: 15q13.3 microdeletions increase risk of idiopathic generalized epilepsy. Nat Genet 2009; 41: 160-162.

28 van Bon BW, Mefford HC, Menten B et al: Further delineation of the 15q13 microdeletion and duplication syndromes: a clinical spectrum varying from non-pathogenic to a severe outcome. J Med Genet 2006; 46: 511-523.

29 Shinawi M, Schaaf CP, Bhatt SS et al: A small recurrent deletion within $15 q 13.3$ is associated with a range of neurodevelopmental phenotypes. Nat Genet 2009; 41: 1269-1271.

30 Freedman R, Adler L, Myles-Worsley M et al: Inhibitory gating of an evoked response to repeated auditory stimuli in schizophrenic and normal subjects. Archives Gen Psychiatr 1996; 53: 1114-1121.

31 Shaikh M, Hall MH, Schulze $K$ et al: Do COMT, BDNF and NRG1 polymorphisms influence P50 sensory gating in psychosis? Psychol Med 2011; 41: 263-276.

32 Bramon E, Rabe-Hesketh S, Sham P, Murray RM, Frangou S: Meta-analysis of the P300 and P50 waveforms in schizophrenia. Schizophr Res 2004; 70: 315-329.

33 Adler LE, Pachtman E, Franks RD, Pecevich M, Waldo MC, Freedman R: Neurophysiological evidence for a defect in neuronal mechanisms involved in sensory gating in schizophrenia. Biol Psychiatry 1982; 17: 639-654.

34 Hall MH, Rijsdijk F, Kalidindi S et al: Genetic overlap between bipolar illness and event-related potentials. Psychol Med 2007; 37: 667-678.

35 Hall MH, Rijsdijk F, Picchioni $M$ et al: Substantial shared genetic influences on schizophrenia and event-related potentials. Am J Psychiatry 2007; 164: 804-812.

36 Franks R, Adler L, Waldo M, Alpert J, Freedman R: Neurophysiological studies of sensory gating in mania: comparison with schizophrenia. Biol Psychiatry 1983; 18: 989-1005.

37 Freedman R, Adler L, Waldo M, Pachtman E, Franks R: Neurophysiological evidence for a defect in inhibitory pathways in schizophrenia: comparison of medicated and drug-free patients. Biol Psychiatry 1983; 18: 537-551.

38 Freedman R, Adler LE, Gerhardt GA et al: Neurobiological studies of sensory gating in schizophrenia. Schizophr Bull 1987; 13: 669-678.

39 Nagamoto HT, Adler LE, Waldo MC, Freedman R: Sensory gating in schizophrenics and normal controls: effects of changing stimulation interval. Biol Psychiatry 1989; 25: 549-561.

40 Baker N, Staunton M, Adler L et al: Sensory gating deficits in psychiatric inpatients: relation to catecholamine metabolites in different diagnostic groups. Biol Psychiatry 1990; 27: 519-528.

41 Judd LL, McAdams L, Budnick B, Braff DL: Sensory gating deficits in schizophrenia: new results. Am J Psychiatry 1992; 149: 488-493.

42 Ward PB, Hoffer LD, Leibert B, Catts SV, O'Donnell M, Adler LE: Replication of a P50 auditory gating deficit in Australian patients with schizophrenia. Psychiat Res 1996; 64: 121-135.

43 Clementz BA, Geyer MA, Braff DL: P50 suppression among schizophrenia and normal comparison subjects: a methodological analysis. Biol Psychiatry 1997; 41: 1035-1044.

44 Clementz BA, Geyer MA, Braff DL: Multiple site evaluation of P50 suppression among schizophrenia and normal comparison subjects. Schizophr Res 1998; 30: 71-80.

45 Olincy A, Martin L: Diminished suppression of the P50 auditory evoked potential in bipolar disorder subjects with a history of psychosis. Am J Psychiatry 2005; 162 43-49.

46 Schulze KK, Hall MH, McDonald C et al: P50 auditory evoked potential suppression in bipolar disorder patients with psychotic features and their unaffected relatives. Bio Psychiatry 2007; 62: 121-128.

47 Sanchez-Morla EM, Garcia-Jimenez MA, Barabash A et al: P50 sensory gating deficit is a common marker of vulnerability to bipolar disorder and schizophrenia. Acta Psychiatr Scand 2008; 117: 313-318.

48 Siegel C, Waldo M, Mizner G, Adler L, Freedman R: Deficits in sensory gating in schizophrenic patients and their relatives. Arch Gen Psychiatry 1984; 41: 607-612.

49 Waldo MC, Adler LE, Freedman R: Defects in auditory sensory gating and their apparent compensation in relatives of schizophrenics. Schizophr Res 1988; 1: $19-24$.

50 Waldo M, Myles-Worsley M, Madison A, Byerley W, Freedman R: Sensory gating deficits in parents of schizophrenics. Am J Med Genet 1995; 60: 506-511. 
51 Stevens KE, Freedman R, Collins AC et al: Genetic correlation of inhibitory gating of hippocampal auditory evoked response and alpha-bungarotoxin-binding nicotinic cholinergic receptors in inbred mouse strains. Neuropsychopharmacol 1996; 15: 152-162.

52 Clementz B, Geyer M, Braff D: Poor P50 suppression among schizophrenia patients and their first-degree biological relatives. Am J Psychiatry 1998; 155: 1691-1694.

53 Waldo MC, Adler LE, Leonard $\mathrm{S}$ et al: Familial transmission of risk factors in the first-degree relatives of schizophrenic people. Biol Psychiatry 2000; 47: 231-239.

54 Young $\mathrm{D}$, Waldo $\mathrm{M}$, Rutledge $\mathrm{JH}$, Freedman R: Heritability of inhibitory gating of the P50 auditory-evoked potential in monozygotic and dizygotic twins. Biol Psychiatry 1996; 33: 113-117.

55 Hall MH, Schulze K, Rijsdijk F et al: Heritability and reliability of P300, P50 and duration mismatch negativity. Behav Genet 2006; 36: 845-857.

56 Anokhin AP, Vedeniapin AB, Heath AC, Korzyukov O, Boutros NN: Genetic and environmental influences on sensory gating of mid-latency auditory evoked responses: a twin study. Schizophr Res 2007; 89: 312-319.

57 Thaker GK: Neurophysiological endophenotypes across bipolar and schizophrenia psychosis. Schizophr Bull 2008; 34: 760-773.

58 Clayton D: A generalization of the transmission/disequilibrium test for uncertainhaplotype transmission. Am J Hum Genet 1999; 65: 1170-1177.

59 Abecasis GR, Cardon LR, Cookson WO: A general test of association for quantitative traits in nuclear families. Am J Hum Genet 2000; 66: 279-292.

60 Abecasis GR, Cookson WO, Cardon LR: Pedigree tests of transmission disequilibrium. Eur J Hum Genet 2000; 8: 545-551.

61 Bramon E, Rabe-Hesketh S, Sham P, Murray RM, Frangou S: Meta-analysis of the P300 and P50 waveforms in schizophrenia. Schizophr Res 2004; 70: 315-329.
62 Hall MH, Schulze K, Sham P et al: Further evidence for shared genetic effects between psychotic bipolar disorder and P50 suppression: a combined twin and family study. Am J Med Genet 2008; 147B: 619-627.

63 Illot NE, Saudino KJ, Asherson P: Genetic influences on attention deficit hyperactivity disorder symptoms from age 2 to 3: a quantitative and molecular genetic investigation. BMC Psychiatry 2010; 10: 102.

64 Zhang H, He J-W, Gao G et al: Polymorphisms in the HOXD4 gene are not associated with peak bone mineral density in Chinese nuclear families. Acta Pharmacol Sinica 2010; 31: 977-983.

65 Gordon D, Heath SC, Liu X, Ott J: A transmission/disequilibrium test that allows for genotyping errors in the analysis of single-nucleotide polymorphism data. Am J Hum Genet 2001; 69: 371-380.

66 Mitchell AA, Cutler DJ, Chakravarti A: Undetected genotyping errors cause apparent overtransmission of common alleles in the transmission/disequilibrium test. Am J Hum Genet 2003; 72: 598-610.

67 Lai IC, Hong CJ, Tsai SJ: Association study of a nicotinic receptor variant with schizophrenic disorders. Neuropsychobiol 2001; 43: 15-18.

68 Gault J, Robinson M, Berger R et al: Genomic organization and partial duplication of the human alpha7 neuronal nicotinic acetylcholine receptor gene (CHRNA7). Genomics 1998; 52: 173-185.

69 de Lucas-Cerrillo AM, Maldifassi MC, Arnalich F et al: Function of partially duplicated human $\alpha 7$ nicotinic receptor subunit CHRFAM7A gene: potential implications for the cholinergic anti-inflammatory response. J Biol Chem 2011; 286: 594-606.

70 Araud T, Graw S, Berger R et al: The chimeric gene CHRFAM7A, a partial duplication of the CHRNA7 gene, is a dominant negative regulator of $\alpha 7^{*} \mathrm{nAChR}$ function. Biochem Pharmacol 2011; 82: 904-914.

71 Makoff A, Flomen R: Common inversion polymorphisms and rare microdeletions at 15q13.3. Eur J Hum Genet 2009; 17: 149-150.

Supplementary Information accompanies the paper on European Journal of Human Genetics website (http://www.nature.com/ejhg) 